\title{
Oxygenated Diesel Fuels from Waste Vegetable Oil
}

\author{
S. Arunkumar ${ }^{1}$, N. Jeeva ${ }^{2}$, P. Balaji ${ }^{3}$, M. Muthu ${ }^{4}$ \\ ${ }_{1,2,3}$ (Thermal engineering, BharathidasanCollege/Anna University,India) \\ ${ }^{4}$ (CAD/CAM, Jayalakshimi College/Anna University,India)
}

\begin{abstract}
Vegetable oils and animal fats (triglycerides) were the first liquid fuels used in the rise of civilization, and now again are a potential source of alternate diesel fuel. They are 20 times as viscous as diesel fuel, however, and so form carbon deposits on diesel cylinders and injectors. They are also typically \%3$\$$ S/gallon, and so are too expensive to compete economically with diesel today. A number of solutions have been proposed for these problems, including transesterification, dilution, pyrolysis and Microemulsification The viscosity can be lowered by transesterification of the triglycerides with methanol or ethanol to form fatty acid esters. This cleaves the fat molecule and removes the glycerine, yielding a viscosity comparable to that of diesel. The heat of combustion is $95 \%$ of that for conventional diesel (on a volume basis). They have a Cetane number of 50-80 (compared to 42 for diesel). The cost of the fuel can be reduced by using waste vegetable cooking oils. There are 350 million gallons of waste vegetable oil produced annually in the U.S.A., and various quantities available in other countries. We have developed a process for making the esters from waste vegetable oils and we call the fuel "M-Diesel". The oil is reacted with sodium hydroxide dissolved in methanol. A sufficient quantity of alkali is used to neutralize the fatty acids in the waste oil plus $0.3 \%$ excess. A batch of 300 gallons was made for testing. We have tested the fuel in a Denver public bus and find power comparable to that of diesel. A 30\% blend with diesel reduced smoke opacity to $60 \%$ of that from diesel, while neat M-Diesel reduced the opacity to $26 \%$ of that of diesel.
\end{abstract}

Keywords: Diesel fuel, waste cooking oils, transesterification, catalysts, diesel emissions.

\section{Introduction}

The properties of a typical diesel fuel, soybean oil and the methyl ester of soybean oil, relevant to use as a diesel fuel, are listed in From this it can be seen that the viscosity of vegetable oils is 20 times that of diesel, while that of the methyl ester is only about twice that of diesel. Therefore, the conventional injectors of diesel engines give a good spray pattern with ester fuels, but not with vegetable oils. The energy content of the ester is about $90 \%$ of that of diesel on a weight basis, but about $95 \%$ on a volume basis. The esters contain about $10 \%$ oxygen by weight. performed engine and vehicle tests in light and heavy trucks on the methyl esters of soybean oil, MES0.19 They found no problems encountered in 40,500 km and wear properties were similar with the two fuels. However, it was necessary to change the lubricating oil more often because of the low volatility of the ester in the crankcase. The power, torque and volumetric brake specific fuel consumption of MESO in an unmodified indirect injection diesel engine reflected the net volumetric heating values. Smoke and $\mathrm{CO}$ decreased with the ester fuel. The material compatibility of a number of polymers and metals were compared to diesel. Ten common polymers were tested: eight were unaffected or acceptable; nitrile rubber and polyurethane foams deteriorated unacceptably. No degradation of aluminum, brass, steel or phosphatized fuel tank was observed.19 Two 13 ton VW trucks accumulated130,000 km using MESO. Fuel consumption was 24\% higher than for these trucks operated on diesel. Engine wear was normal, but lubricating oil was changed more often due to the higher dilution rate. Trucks were also operated on blends of MESO and diesel. The oil dilution rate decreased in proportion to the amount of diesel in the fuel. ${ }^{*} \mathrm{O}$ A number of other engine and vehicle tests on vegetable oil esters have been reported with similar results. ' $6.2^{\prime}-23$ In particular it is reported that the ester fuels show higher thermal efficiencies than did No. 2 diesel fuel and have lower smoke emissions. The Cetane number of the methyl esters of vegetable oils seems to be in some doubt. Early reports gave Cetane numbers in the range 40-60 for vegetable oil estersI while others give Cetane numbers in the range 60-80.24 Recent experiments by Bagby et al. show that methyl esters of saturated fatty acids with 1418 carbon chains have a Cetane of about $75 .{ }^{\circ *}$ Klopfenstein reports the Cetane of methyl 
Oxygenated Diesel Fuels from Waste Vegetable Oil

\begin{tabular}{|l|l|l|l|}
\hline FUEL & DIESEL & SOYBEAN OIL & $\begin{array}{l}\text { METHYL ESTER } \\
\text { SOYBEAN OIL }\end{array}$ \\
\hline Flash point & $\begin{array}{l}\text { (a)--not specified in test fuel } \\
\text { diesel. }\end{array}$ & 219 & 178 \\
\hline Density g/ml & $\begin{array}{l}\text { (a)--not specified in test fuel } \\
\text { diesel. }\end{array}$ & 0.923 & 0.885 \\
\hline Viscosity at $38^{\circ} \mathrm{C} \mathrm{mm} / \mathrm{s}$ & $1.6-6$ & 37 & 4.5 \\
\hline Cetane no. (ASTM 613$)$ & 45 & 38 & 45 \\
\hline Cloud point & $9-19$ & -4 & 1 \\
\hline $\begin{array}{l}\text { Net heating value } \mathrm{MJ} / 135.3 \\
3433.5\end{array}$ & 35.3 & 34 & 33.5 \\
\hline
\end{tabular}

Table 1. Properties of a typical diesel fuel, soybean oil and the methyl ester of soybean oil

\section{Oxygenated Disel Fuel Form Waste Vegatble Oil}

Approximately 2.5 billion pounds of waste restaurant fats are collected annually from restaurants and fast food establishments in the world. Currently most of this "waste" is used for animal feeds, pet foods, as a source for fatty acids for industrial use and as a diluent in higher grade inedible fat products. The raw grease is processed to remove water and solids. $2 \mathrm{~s}$ the waste oil typically contains $410 \%$ free fatty acids (FFA) which are more difficult to esterify than the triglycerides. We have developed a process for converting the waste cooking oils to the methyl or ethyl esters for use as an alternate oxygenated diesel substitute or blending stock. Waste vegetable oil differs from virgin oils by having 3-8\% free fatty acids (FFAs). Each oil must be titrated for FFA before reaction. Methanol equal to $15 \%$ of the WV0 (50\% over stoichiometric) is reacted with sutXcient sodium hydroxide to neutralize the FFAs plus an additional $0.3 \%$ to make the mixture basic. The methanol is added to well stirred $\mathrm{WV0}$ at $50^{\circ} \mathrm{C}$ and the mixture stirred vigorously for $30 \mathrm{~min}$. The resulting two phase liquid separates into two layers as it cools, the ester fuel on top and a mixture of soap and glycerine on the bottom. Depending on the concentration of FFA, the lower layer may be liquid or may gel due to the concentration of soap. About $200 \mathrm{ppm}$ of soap remains in the ester fuel. This can be removed by titration with organic or mineral acid. We call the ester fuel "M-Diesel" (for methanol-diesel).

\section{Fatty Acid Esters As Diesel Fuels}

The vegetable oil viscositycould be reduced by reacting methanol or ethanol with the triglycerides to produce a fatty acid ester and glycerol.' The fatty acid radicals in animal fats are generally saturated, long chain molecules with typically 16 or 18 carbon atoms. In vegetable oils there may be 1-3 double bonds. 14 The effects on the fuel properties of these minor variations in the fatty acids are minimal. The properties of some pure esters are compared to diesel .

\section{Methyl Ester Testing In Diesel Engines}

The properties of a typical diesel fuel, soybean oil and the methyl ester of soybean oil, relevant to use as a diesel fuel, are listed in Table 2.18 From this it can be seen that the viscosity of vegetable oils is 20 times that of diesel, while that of the methyl ester is only about twice that of diesel. Therefore, the conventional injectors of diesel engines give a good spray pattern with ester fuels, but not with vegetable oils. The energy content of the ester is about $90 \%$ of that of diesel on a weight basis, but about $95 \%$ on a volume basis. The esters contain about $10 \%$ oxygen by weight.

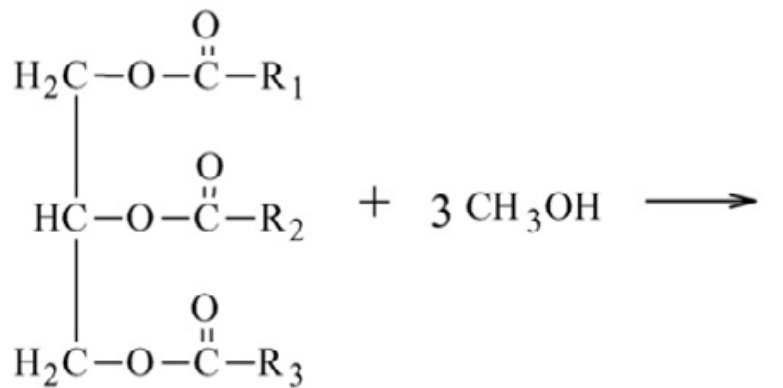<smiles>[R]C(=O)OC</smiles><smiles>OCC(O)CO</smiles> 
The above reaction, which is known as esterification, increases the possibility of producing biodiesel at lower costs. Although pure free fatty acids are not as abundantly available as pure triglycerides, the low cost of high-acid oils is attractive enough for researchers to strive for a better understanding of this reaction. The source of an acid oil, its FFA content, the initial amount of methanol, amount of catalyst and time are important parameters which influence the final conversion of the reaction $[10,11,12,13,14]$. In order to achieve a better insight of the pretreatment step, this study attempts to investigate the esterification reaction with a potential feedstock for future industrial biodiesel production plants. In other words, a by-product of an operating vegetable oil refinery, containing high amounts of free fatty acids, was selected and the reaction conditions were investigated experimentally.

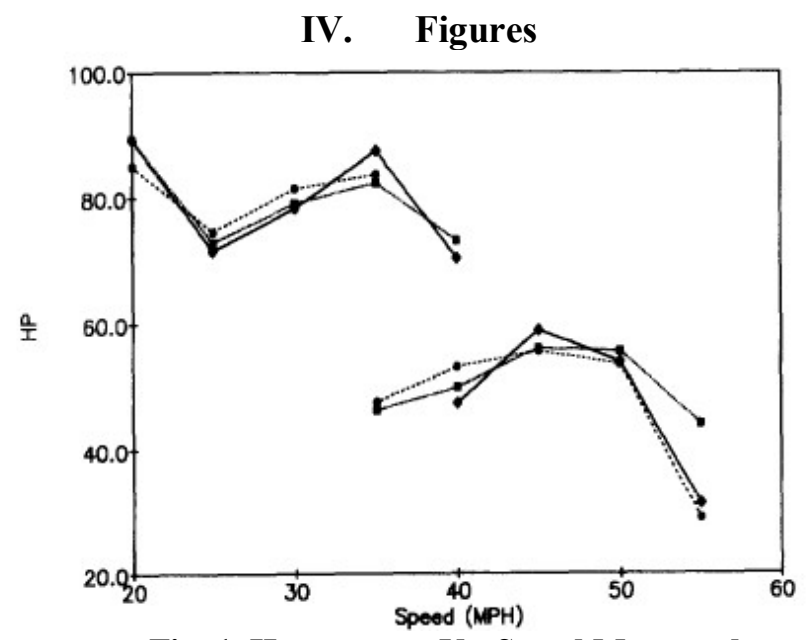

Fig. 1. Horsepower Vs. Speed Measured

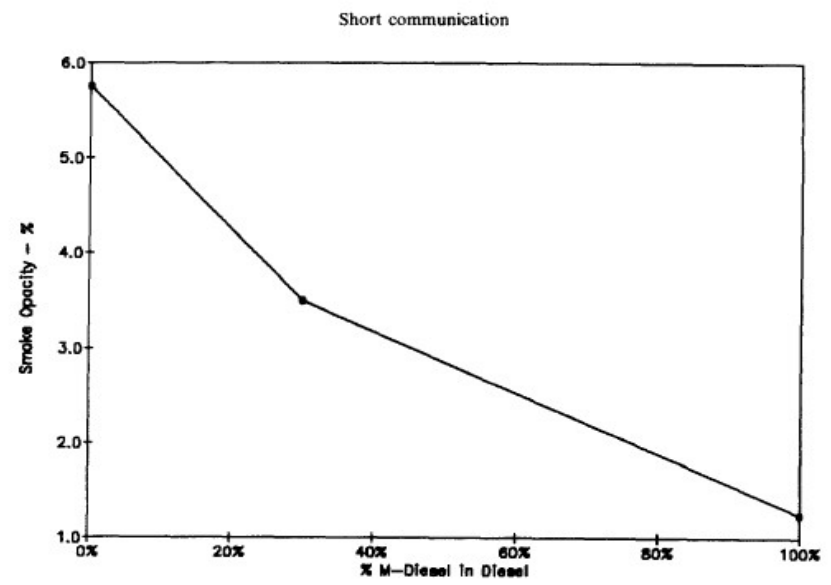

Fig. 2. Smoke Opacity Vs. \% M-Diesel In Conventional Diesel.

\section{Conclusion}

The methyl and ethyl esters of vegetable oils are equal to or superior to conventional diesel in many ways and may ultimately be used to replace petroleum diesel. However, the cost is still above that of conventional diesel. We believe that the use of the methyl ester of waste vegetable oil provides an early economical source of a clean, renewable, alternative oxygenated diesel fuel and that it is economically viable today.

\section{References}

[1] J. J. Bruwer, B. v. D. Boshoff, F. J. C. Hugo, L. M. du Plessis, J. Fuls, C. Hawkins, A. N. van der Walt and A. Engelbrecht, Sunflower seed oil as an extender for diesel fuel in agricultural tractors. Symposium for South African Institute of Agricultural Engineers, Pretoria (1980).

[2] R. A. Faxaalare and C. R. Smith (Eds), Beyond the Energy Crisis-Opportunity and ChalIenge. Vol. III. Third International Conference on Energy Use Management. Pergamon Press, Oxford (1981).

[3] J. Fuls and F. J. C. Hugo, On-farm preparation of sunflower oil esters for fuel. D V . 1595-1602 in Ref. 2 (1981).

[4] C. S. Hawkins, J. Fuls and F. J. C. Hugo, Laboratory procedures for investigating some fuel properties of sunflower oil esters in diesel engines. pp. 161 1-1617 in Ref. 2 (1981).

[5] K. R. Kaufman, M. Jiejewski, M. Morohl and A. E. Jones, Sunflower oil and methyl ester as fuels for diesel engines. pp. 1635-1643 in Ref. 2 (1981). 
[6] Proceedings of the Fifth International Alcohol Fuel Technology Symposium, (May 1982) New Zealand.

[7] DSIR, Auckland. G. H. Pischinger, R. W. Siekmann, A. M. Falcon and F. R. Femandes, Results of engine and vehicle tests with methyl esters of plant oils as alternative diesel fuels. In Ref. 65 (1982).

[8] M. Geofrey, I. B. Smith, J. H. Blackbum, R. Pinchin and A. V. da Rocha, Esters as a future diesel fuel: an initial assessment. In Ref. 6 (1982).

[9] Alcohol and Vegetable Oil as Alternative Fuels. Proceedings of Regional Workshops, Purdue Univ., West LaFayette, Indiana (1981).

[10] Vegetable Oil Fuel. Proceedings of the International Conference on Plant and Vegetable Oils as Fuels. The American Society of Agricultural Engineers, ASAE Publication 4-82 (1982).

[11] Vegetable Oil as Diesel Fuel: Seminar III. Agricultural Reviews and Manuals, Agricultural Research Service, 